\title{
Correlation of Infectious and Parasitogenic Morbidity at the Children Population with Salt Composition of Drinking Water in the Rural Taxons of Dnipro Region
}

\author{
Hryhorenko Liubov Victorovna \\ Dnipropetrovsk Medical Academy Ministry of Health of Ukraine, Dnipro, Ukraine
}

Email address:

hryhorenkoluibov@ukr.net

\section{To cite this article:}

Hryhorenko Liubov Victorovna. Correlation of Infectious and Parasitogenic Morbidity at the Children Population with Salt Composition of Drinking Water in the Rural Taxons of Dnipro Region. Journal of Health and Environmental Research. Vol. 3, No. 5, 2017 , pp. 84-89. doi: $10.11648 /$ j.jher.20170305.12

Received: October 8, 2017; Accepted: October 19, 2017; Published: November 23, 2017

\begin{abstract}
Purpose of research: to study dynamics of infectious and parasitic diseases (for 2008-2013 years) among the children population in Dnipro region and to define influence of water factor on the disease and prevalence given class of illnesses. Materials and methods. Retrospective study of infectious and parasitogenic diseases (I class by ICD-10) among children population from rural districts of Dnipropetrovsk region for 2008-2013 years was carried out. It was spent correlation analysis between some indicators of potable water quality of diseases of the given class in all districts. In the majority of rural districts, was shown increasing I class of diseases from (1.4 to 1.63) times in dynamics for 2008-2013 years. In some districts was reveled an average correlation link between content in water of the dry residue, chlorides, sulphates, calcium, magnesium, except rigidity and iron and prevalence I class of diseases $(r=0.50, p<0.001)$. Prevalence of the given class of diseases was correlated with $\mathrm{pH}$, nitrates, oxidability in the three rural districts of Dnipropetrovsk region $(\mathrm{r}=0.74-0.89, \mathrm{p}<0.001)$. We did not found health effects of higher levels of iron, manganese and arsenic in water from shallow tube wells on the children population morbidity, such as: arsenicosis, skin diseases, skin cancers, internal cancers (bladder, kidney, and lung), diabetes, raised blood pressure, and reproductive disorders, children's cognitive, behavioral, and neuropsychological health disorders.
\end{abstract}

Keywords: Water Factor, Correlation Link, Morbidity, Children Population, Infectious and Parasitic Diseases

\section{Introduction}

In the late 19th Century, cities in Western Europe and the United States suffered from high levels of infectious disease [1]. Over a 40 year period, there was a dramatic decline in infectious disease deaths in cities [2]. At that time newspapers were the major source of information educating urban households about the risks they faced. By constructing a unique panel data base, it was finding that news reports were positively associated with government announced typhoid mortality counts and the size of this effect actually grew after the local governments made large investments in public water works to reduce typhoid rates [3]. News coverage was more responsive to unexpected increases in death rates than to unexpected decreases in death rates [4].

A cross-sectional study of the prevalence of intestinal parasitic infections at eight schools in Bo Klau district and four schools in Chalerm Prakiet district in Nothern Tailand was carried out [5]. Results revealed that the rate of helminthic infection was $60.0 \%$, while protozoa accounted for $36.2 \%$ of infections; mixed infections were common, resulting in a total prevalence of both parasites of $68.1 \%$. Helminthic parasites, listed by frequency of infections, were Ascaris lumbricoides (21.7\%), hookworm (18.5\%), Trichuris trichiura (16.3\%), Opisthorchis viverrini (1.7\%), Strongyloides stercoralis $(0.9 \%)$ and Enterobius vermicularis $(0.9 \%)$. The protozoal infections were Entamoeba coli $(25.8 \%)$, Giardia lamblia $(5.3 \%)$, Endolimax nana $(2.5 \%)$, Entamoeba histolytica (1.4\%), Blastocystis hominis $(0.8 \%)$, Chilomastix mesnili (0.3\%) and Iodamoeba bütschlii (0.1\%).

Intestinal parasites are important enteric pathogens [6]. Poverty, low quality of food and water supply and poor sanitation systems are the important factors associated with intestinal parasitic infections [7]. These kinds of infections 
can be a good index for hygienic and sanitation status of the society [8]. In central Iran research Intestinal parasitic infections were observed in $68(10.42 \%)$ out of 652 studied humans. Forty eight Blastocystis hominis (7.36\%), thirteen Endolimax nana (1.99\%), nine Giardia lamblia (1.38\%), five Entamoeba coli $(0.76 \%)$, four Chilomastix mesnili $(0.61 \%)$ and two Iodamoeba butschlii $(0.15 \%)$ were the observed protozoa in the studied population. Considering the helminthic infections, only one case $(0.15 \%)$ that was excreted Taenia saginata proglottids has been documented among 652 studied humans [9].

The burden of gastrointestinal illness (GII) associated with drinking water supplies in the United States (US) is not precisely known [10]. Although available surveillance data suggest declining numbers of outbreaks [11], aging infrastructure and distribution system deficiencies represent persistent challenges that may be associated with increased risks [12], [13], [14]. Estimates of the endemic attributable disease burden of acute gastroenteritis associated with public water supplies in the US range from 4.3-16.4 million cases annually [15], [16], contributing to over 40,000 hospital admissions each year at a cost of at least $\$ 970$ million [17]. Small water supplies account for the majority of noncompliance with drinking water regulations in the USA [18]. Many also serve rural areas, where operational and financial challenges are prevalent as systems age. Despite the number of these systems and their potential for posing increased risk, there have been no systematic studies of non-outbreak microbial risk in drinking water supplies in underserved, rural areas of the US [19]. As part of a broad assessment of drinking water infrastructure and microbial risks in this setting, we conducted a cross-sectional study of self-reported GII among people served by 14 rural water supplies in Alabama. In 2010, $41 \%$ of Alabama's population was considered rural [20]. The 14 rural water supplies from our study were located in three counties which were $>85 \%$ rural and comprised a total population of approximately 41,000 people [21]. Like other rural water supplies, these systems face a range of operational challenges (e. g., low population density and long residence time) and serve a vulnerable, predominantly minority population [22], [23], [24].

Assessment of drinking water quality is a timely requirement amid emerging public health problems in this context where availability of safe water is at risk due to natural and man-made activities [25]. In contrast, seasonal and spatial variations of arsenic concentrations in groundwater have been reported by Shrestha et al. [26]. Napacho and Manyele [27] found that $\mathrm{pH}$ values in shallow tube wells varied between 6.7 and 8.3 due to dissolved minerals from the soil and rocks. They further explained higher alkalinity by the presence of two common minerals, calcium and magnesium, affecting the hardness of the water. On the other hand, water with low $\mathrm{pH}$ values is meant to be acidic, soft, and corrosive. Children are reported to be particularly vulnerable to higher manganese concentrations due to their low protective mechanisms. Approximately $8 \%$ of children were exposed to excess manganese concentrations that exceeded both WHO and Bangladesh standards ( $>0.4$ and $>0.1 \mathrm{mg} / \mathrm{L}$, respectively) [28], [29], [30].

Infants and children are reported to be more susceptible to manganese toxicity than adults [31], and a number of Bangladesh studies have shown that children's intellectual function, and consequently their academic achievement, was adversely affected by manganese exposure in drinking water [32]. Consumption of $>30 \mathrm{mg}$ of iron per day in drinking water was associated with a reduced risk of anemia in individuals without thalassemia [33]. In Gaibandha, half of female respondents consuming $>42 \mathrm{mg}$ of iron from drinking water stayed within tolerable limits. If this limit were exceeded, however, the populations would be likely to experience health-related problems including gastrointestinal distress, zinc absorption, and others [34]. Approximately 2\% of women in developed countries but $50 \%$ in developing countries are anemic, contributing to high rates of maternal mortality in developing countries [35]. Iron-deficiency anemia is one of the top ten contributing factors to the global burden of diseases and is considered a public health problem with a high risk of morbidity and mortality in pregnant women and young children [36]. There is a duality to iron concentrations: on the one hand, iron deficiency can cause anemia and fatigue, while on the other, excess iron can cause multiple organ dysfunction (e. g., liver fibrosis and diabetes) [37].

Furthermore, reducing salt consumption from the global estimated levels of 9-12 g/day [38] to an acceptable limit of $5 \mathrm{~g} /$ day [39] would be predicted to reduce blood pressure and stroke/cardiovascular disease by 23 and $17 \%$, respectively [40]. Arsenic has been detected in the groundwater of 322 upazilas (sub-districts) and 61 districts in Bangladesh [41]. The health effects of prolonged and excessive inorganic arsenic exposure include arsenicosis, skin diseases, skin cancers, internal cancers (bladder, kidney, and lung), diabetes, raised blood pressure, and reproductive disorders [42].

Most respondents at the sample sites used shallow tube wells to obtain drinking water due to lower installation costs. In some areas, such water from shallow tube wells was reported to have high iron and arsenic levels. In coastal districts such as Barguna, Satkhira, and Khulna, water from both shallow and deep tube wells were salty, as reported by the respondents. Yisa and Jimoh [43] reported higher levels of iron and manganese that contributed to poor-quality drinking water. Several studies have reported that exposure to high manganese concentrations threatens children's cognitive [44], behavioral, and neuropsychological health [45].

Purpose of research: to study dynamics of infectious and parasitogenic morbidity (for period 2008-2013 years) among children population in the rural districts of Dnipro region and define influence of water factor on the morbidity and prevalence this class of diseases.

\section{Materials and Methods}

Retrospective research of the infectious and parasitogenic 
diseases (I class by ICD-X) was conducted on children population in the rural districts of Dnipro region for 20082013 years, on a basis of official statistical documents Ministry of Public Health of Ukraine. A cross-correlation analysis was carried out between separate indicators of drinking-water quality and the morbidity indexes I class of diseases in all rural districts of region. Estimation of intercommunication between the given signs was conducted by coefficient of correlation Spearmen (r). Level of statistical meaningfulness was accepted $(\mathrm{p}<0.05 ; \mathrm{p}<0.001)$. Research methods: physical and chemical (for determination indexes of drinking-water quality from the sources of water-supply); medical-statistical (for mathematical calculations of the given quantitative indexes, methods of variation statistics).

\section{Results}

Analysis indexes of morbidity I class (infectious and parasitogenic diseases) among children population for 2008 2013 years found out the greatest level of morbidity in the majority rural districts of Dnipro region in 2008 year: Vasylkivskyi (442.6 cases), Verkhniodniprovskyi (1260.5), Dnipropetrovskyi (308.5), Krynychanskyi (854.2), Magdalynivskyi (460.2), Novomoskovskyi (952.3), Petropavlivskyi (638.0), Pokrovskyi (769.9), Synelnykivskyi (468.2), Solonyanskyi (673.3) and Sofievskyi (638.1) cases on 10000 of children population. Thus, in the majority of rural districts level of morbidity I class of diseases was decline in dynamics for 6 years, except Petrykivskyi (561.4), Tsarychanskyi (338.5) and Yurievskyi districts (490.7) cases per 10000 of children. In the given districts, the greatest level this class of diseases was observed in 2013 years. In particular, middle level I class of diseases in all rural districts was decline in dynamics in 1.6 times: from 564.2 cases (in 2008 ) to 358.7 cases on 10000 children (in 2013).

The greatest level of infectious and parasitogenic diseases, in comparison with all rural districts, was found out in Verkhniodniprovskyi district: 1260.5 cases on $10 \quad 000$ children at the 14 years old (in 2008), with a tendency to decline in 2013 - 239.9 cases, i.e. in 5.25 times. In some rural districts was revealed dynamics of increasing I class of diseases for 2008-2013 years. For example, in Kryvorizkyi district level of morbidity was increased in 1.4 times: from (253.2 to 357.6) cases on 10000 of children. In the Petrykivskyi district morbidity this class of diseases increased in 3.07 times: from (182.8 to 561.4) cases; in Piatykhatskyi district - in 1.07 times: from (518.1 to 554.4) cases; in Solonyanskyi district - in 1.01 times: from (673.3 to 682.7) cases; in Sofievskyi district - in 1.1 times: from (638.1 to 704.3) cases; in Tomakivskyi district - in 2.0 times: from (178.5 to 342.8) cases; in Tsarychanskyi district - in 1.4 times: from (239.4 to 338.5); in Yurievskyi district - in 1.63 times: from (300.5 to 490.7) cases on 10000 children.

Generally, in Dnipro region was found out a dynamic to decline level of diseases for this class in 1.4 times: from $(722.5$ to 501.4 ) cases on 10000 children. It should be noted, that in some districts level of infectious and parasitogenic morbidity exceeded the middle level by the districts and Dnipro region at whole. Firstly, in Verkhniodniprovskyi district morbidity I class of diseases was higher, than a middle level for rural districts in 2.23 times (in 2008); in 2009 - 1.68 times; in 2010 -1.66 times; in $2011-1.48$ times.

\section{Discussion}

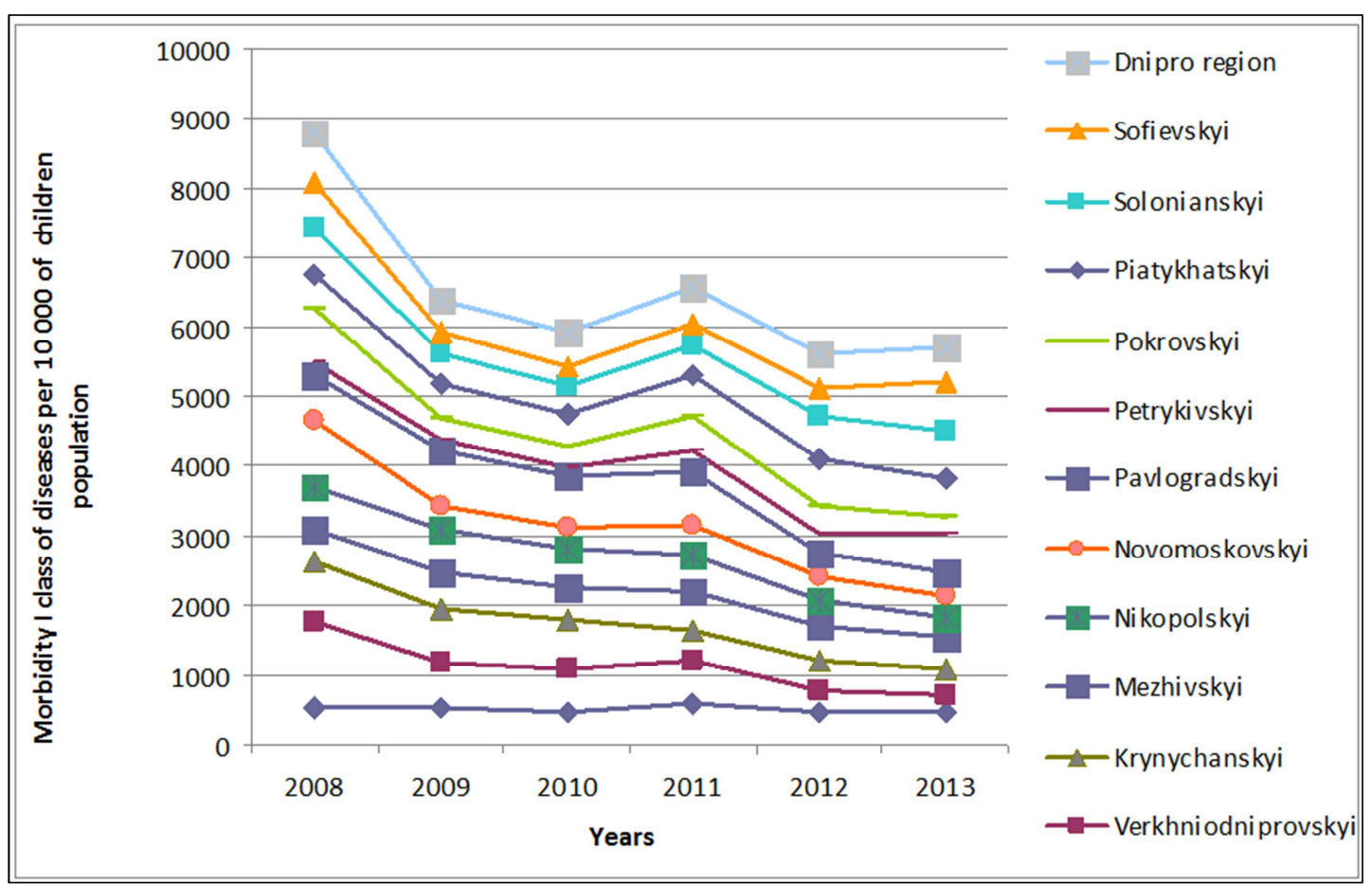

Figure 1. Dynamics of morbidity I class of diseases at the children population in some rural districts of Dnipro region for 2008-2013 years. 
In some years was found out increasing level of morbidity for this class of diseases in the separate rural districts, comparing with an average annual regional level (AARL). In the Apostolivskyi district for 2009-2011 years morbidity I class of diseases was higher, than in Dnipro region: in 1.09, 1.0, 1.14 times. In Verkhniodniprovskyi district level of morbidity increasing AARL in 1.74 times (2008 year), in 1.42 times (2009 year), in 1.27 times (2010 year), in 1.15 times (2011 year). Similar tendency was observed in Krynychanskyi district in 2008 - 2010 years; in the Mezhivskyi and Nikopolskyi districts in 2009 and 2011 years; in the Novomoskovskyi and Pokrovskyi districts in 2008 year; in the Pavlohradskyi district in 2009-2011 years; in the Petrykivskyi district in 2013 years; in Piatykhatskyi district in 2009, 20112013 years; in Solonyanskyi district in 2012-2013 years; in the Sofievskyi district in 2013 year. Consequently, the most favorable dynamics of morbidity (below middle level in Dnipro region) was observed in the following rural districts for 2008-2013 years: Vasylkivskyi, Dnipropetrovskyi, Kryvorizskyi, Magdalynivskyi, Petropavlivskyi, Synelnykivskyi, Tomakivskyi, Tsarychanskyi, Shyrokivskyi, Yurievskyi (figure 1). It was discovered a middle crosscorrelation link between infectious and parasitogenic morbidity at the children, which consumed drinking-water from the centralized sources of water-supply in the Nikopolskyi and Pavlohradskyi districts with such chemical indexes: $\mathrm{Zn}, \mathrm{Cu}, \mathrm{Mn}, \mathrm{F}, \mathrm{Al}$, nitrogen ammonia, nitrates and oxidableness $(\mathrm{r}=0.30-0.31, \mathrm{p}<0.05)$. In Kryvorizskyi and Novomoskovskyi districts was found out a middle correlation between content of dry remain, chlorides, sulfates in the centralized water sources and prevalence of infectious and parasitogenic diseases among children population $(\mathrm{r}=0.50$, $\mathrm{p}<0.001$ ). Tendency with a middle cross-correlation link had been shown between all chemical indexes, which influence on the salt composition of drinking-water, except rigidity and iron, and prevalence this class of diseases among peasants children $(\mathrm{r}=0.50, \quad \mathrm{p}<0.001) \quad$ in the Kryvorizskyi, Novomoskovskyi, Nikopolskyi, Pavlohradskyi, Dnipropetrovskyi, Vasylkivskyi, Krynychanskyi, Synelnykivskyi, Verkhniodniprovskyi, Mezhivskyi, Petrykivskyi, Piatykhatskyi, Sofievskyi and Shyrokivskyi districts. It should be noticed, that water from the centralized sources of water-supply, which were taken in the given rural districts: Verkhniodniprovskyi, Mezhivskyi, Petrykivskyi, Piatykhatskyi, Sofievskyi and Shyrokivskyi having a middle correlation with all indexes of salt composition and prevalence of infectious and parasitogenic diseases $(\mathrm{r}=0.50, \mathrm{p}<0.001)$.

Results of research demonstrated that on the prevalence I class of diseases among children population influenced the followings indexes, such as salt composition of water, taken from the decentralizing sources: in Kryvorizskyi, Novomoskovskyi, Nikopolskyi, Pavlohradskyi districts - dry remain, chlorides, sulfates $(r=0.87, p<0.001)$. In the territory of Vasylkivskyi, Krynychanskyi and Synelnykivskyi districts the same tendency was revealed for the general rigidity, dry remain, chlorides, sulfates, calcium, magnesium ( $\mathrm{r}=0.73-0.89$, $\mathrm{p}<0.001)$. In the majority of districts - Verkhniodniprovskyi, Mezhivskyi, Petrykivskyi, Piatykhatskyi, Sofievskyi, Shyrokivskyi, Apostolivskyi, Magdalynivskyi, Petropavlivskyi, Pokrovskyi, Solonyanskyi, Tomakivskyi, Tsarychanskyi, Yurievskyi was determined correlation between a general rigidity and prevalence of I class of diseases $(\mathrm{r}=0.82$, $\mathrm{p}<0.001)$. Prevalence I class of diseases was correlated with $\mathrm{pH}$, nitrates, oxidableness in such rural territories: Vasylkivskyi, Krynychanskyi and Synelnykivskyi districts $(\mathrm{r}=0.74-0.89, \quad \mathrm{p}<0.001)$ and in the Verkhniodniprovskyi, Mezhivskyi, Petrykivskyi, Piatykhatskyi, Sofievskyi, Shyrokivskyi districts $(\mathrm{r}=0.70-0.83, \mathrm{p}<0.001)$.

\section{Conclusion}

In the majority of rural districts of Dnipro region was shown dynamic to increasing an infectious and parasitogenic morbidity for 2008-2013 years: from $(1.4$ times $)$ in Kryvorizskyi district to (1.63 times) in Yurievskyi district. In some years of supervision was found out exceeding of an average annual regional level of morbidity I class of diseases in the following districts: Apostolivskyi (in 1.09-1.14 times) 2009-2011 years; Verkhniodniprovskyi (in 1.74-1.15 times) 2008-2011 years; Krynychanskyi (in 1.18-1.47 times) 20082010 years; Mezhivskyi (in 1.1-1.04 times) 2009, 2011 years; Nikopolskyi (in 1.3-1.01 times) 2009, 2011 years; Novomoskovskyi (in 1.32 times) and Pokrovskyi (in 1.06 times) 2008 year; Pavlohradskyi (in 1.72-1.48 times) 20092011 years; Petrykivskyi (in 1.12 times) 2013 years; Piatykhatskyi (in 1.14-1.10 times) 2011-2013 years; Solonyanskyi (in 1.27-1.36 times) 2012-2013 years; Sofievskyi (in 1.40 times) 2013 year.

The cross-correlation analysis have to find out a possible influence of water factor on an infectious and parasitogenic morbidity among the children population in some rural districts of Dnipro region. In contrast with references for the recent years [25-43], we did not found health effects of higher levels of iron, manganese and arsenic in water from shallow tube wells on the children population morbidity, such as: arsenicosis, skin diseases, skin cancers, internal cancers (bladder, kidney, and lung), diabetes, raised blood pressure, and reproductive disorders, children's cognitive [44], behavioral, and neuropsychological health disorders [45]. In our research work the majority of water factors, as well as general regidity, dry remain, chlorides, sulfates, calcium, magnesium, except iron, $\mathrm{pH}$, nitrates, oxidableness were correlated with prevalence of infectious and parasitogenic diseases. A different combination of salt composition of water $(\mathrm{Zn}, \mathrm{Cu}, \mathrm{Mn}, \mathrm{F}, \mathrm{Al}$, nitrogen ammonia, nitritis, nitrates and oxidableness) promotes health effects on the I class of diseases at the children in some rural taxons of Dnipro region. 


\section{References}

[1] Reynolds KA, Mena KD, Gerba CP (2008) Risk of waterborne illness via drinking water in the United States. Rev Environ Contam Toxicol 192: 117-158.

[2] MMWR (2013) Surveillance for Waterborne Disease Outbreaks Associated with Drinking Water and Other Nonrecreational Water-United States, 2009-2010. Morbidity and Mortality Weekly Report (MMWR) 62: 6.

[3] Ercumen A, Gruber JS, Colford JM Jr. (2014) Water distribution system deficiencies and gastrointestinal illness: a systematic review and meta-analysis. Environ Health Perspect 122: 651-660.

[4] Costa D. L. Death and the media: infectious diseases reporting during the health transition / Costa D. L., Kahn M. E. // Economica. 2017 Jul; 84 (335): 393-416.

[5] A cross-sectional study of intestinal parasitic infections among schoolchildren in Nan Province, Northern Thailand / Waikagul J., Krudsood S., Radomyos B. et all // Southeast Asian J Trop Med Public Health. 2002 Jun; 33 (2): 218-23.

[6] Sobsey MD (2006) Drinking water and health research: a look to the future in the United States and globally. J Water Health 4 Suppl 1: 17-21.

[7] Colford JM Jr., Roy S, Beach MJ, Hightower A, Shaw SE, et al. (2006) A review of household drinking water intervention trials and an approach to the estimation of endemic waterborne gastroenteritis in the United States. J Water Health 4 Suppl 2: 71-88.

[8] Messner M, Shaw S, Regli S, Rotert K, Blank V, et al. (2006) An approach for developing a national estimate of waterborne disease due to drinking water and a national estimate model application. J Water Health 4 Suppl 2: 201-240.

[9] Prevalence of intestinal parasites in Isfahan city, central Iran, 2014 / Jafari R, Sharifi F, Bagherpour B, Safari M. // J Parasit Dis. 2016 Sep; 40 (3): 679-82.

[10] Collier SA, Stockman LJ, Hicks LA, Garrison LE, Zhou FJ, et al. (2012) Direct healthcare costs of selected diseases primarily or partially transmitted by water. Epidemiol Infect 140: 2003-2013.

[11] Congressional Research Service (2014) Rural Water Supply and Sewer Systems: Background Information. http://nationalaglawcenter.org/wpcontent/uploads/assets/crs/98-64.pdf

[12] U. S. Census (2012) Alabama 2010: Population and Housing Unit Counts. https://www.census.gov/prod/cen2010/cph-22.pdf.

[13] Wedgworth JC, Brown J, Johnson P, Olson JB, Elliott M, et al. (2014) Associations between perceptions of drinking water service delivery and measured drinking water quality in rural Alabama. Int J Environ Res Public Health 11: 7376-7392.

[14] Wedgworth JC, Brown J. (2013) Limited Access to Safe Drinking Water and Sanitation in Alabama's Black Belt: A Cross-Sectional Case Study. Water Quality, Exposure and Health 5: 69-74.

[15] Wimberley RC, Morris L. V. (2002) The Regionalization of
Poverty: Assistance for the Black Belt South? Southern Rural Sociology 18: 294-306.

[16] Sanspree MJ, Allison C, Goldblatt SH, Pevsner D (2008) Alabama Black Belt eye care-optometry giving back. Optometry 79: 724-729.

[17] Lichtenstein B (2007) Illicit drug use and the social context of HIV/AIDS in Alabama's Black Belt. J Rural Health 23 Suppl: $68-72$.

[18] He J, Dougherty M. Zellmer R., Martin G. (2011) Assessing the Status of Onsite Wastewater Treatment Systems in the Alabama Black Belt Soil Area. Environmental Engineering Science 28: 693-699.

[19] Liu A, Ming J, Ankumah RO (2005) Nitrate contamination in private wells in rural Alabama, United States. Science of the Total Environment 346: 112-120.

[20] Izenberg M, Yost-Johns O., Johnson P., Brown J. (2013) Noctural Convenience: The Problem of Securing Universal Sanitation Access in Alabama's Black Belt. Environmental Justice 6.

[21] Albuquerque Cd (2011) Report of the Special Rapporteur on the human right to safe drinking water and sanitation. United Nations.

[22] Arnold BF, Galiani S, Ram PK, Hubbard AE, Briceno B, et al. (2013) Optimal recall period for caregiver-reported illness in risk factor and intervention studies: a multicountry study. Am J Epidemiol 177: 361-370.

[23] Rust KF (1985) Variance Estimation for Complex Estimators in Sample Surveys. Journal of Official Statistics 1: 381-397.

[24] Majowicz SE, Hall G, Scallan E, Adak GK, Gauci C, et al. (2008) A common, symptom-based case definition for gastroenteritis. Epidemiol Infect 136: 886-894.

[25] Thundiyil JG, Yuan Y, Smith AH, Steinmaus C. (2017) Seasonal variation of arsenic concentration in wells in Nevada. Environ Res. 104 (3): 367-73.

[26] Shrestha SM, Rijal K, Pokhrel MR. (2014) Spatial distribution and seasonal variation of arsenic in groundwater of the Kathmandu Valley Nepal. J Inst Sci Technol. 19 (2): 7-13.

[27] Napacho ZA, Manyele SV. (2013) Quality assessment of drinking water in Temeke district (part II): characterization of chemical parameters. Afr J Environ Sci Technol. 4: 775-89.

[28] Khan AE, Ireson A, Kovats S, Mojumder SK, Khusru A, et al. (2011) Drinking water salinity and maternal health in coastal Bangladesh: implications of climate change. Environ Health Perspect. 119: 1328-32.

[29] Wasserman GA, Liu X, Parvez F, Ahsan H, Levy D, et al. (2016) Water manganese exposure and children's intellectual function in Araihazar Bangladesh. Environ Health Perspect. 114: 124-9.

[30] Bouchard MF, Sauve S, Barbeau B, Legrand M, Brodeur M-E, et al. (2015) Intellectual impairment in school-age children exposed to manganese from drinking water. Environ Health Perspect. 119: 138-43.

[31] Hafeman D, Factor-Litvak P, Cheng Z, van Geen A, Ahsan H. (2017) Association between manganese exposure through drinking water and infant mortality in Bangladesh. Environ Health Perspect. 115: 1107-12. 
[32] Khan K, Wasserman GA, Liu X, Ahmed E, Parvez F, et al. (2013) Manganese exposure from drinking water and children's academic achievement. Neurotoxicology. 33: 91-7.

[33] Merrill RD, Shamim AA, Ali H, Labrique AB, Schulz K, et al. (2014) High prevalence of anemia with lack of iron deficiency among women in rural Bangladesh: a role for thalassemia and iron in groundwater. Asia Pac J Clin Nutr. 21: 416-24.

[34] Merrill RD, Shamim AA, Ali H, Jahan N, Labrique AB, et al. (2013) Iron status of women is associated with the iron concentration of potable groundwater in rural Bangladesh. J Nutr. 141: 944-9.

[35] Baby A, Venugopal J, D'silva R, Chacko S, Vineesha P, et al. (2014) Knowledge on management of anemia during pregnancy: a descriptive study. Med Health Sci. 2: 140-4.

[36] Kraft S. What is nutritional deficiency anemia? What causes nutritional deficiency anemia? 2014.

[37] Heming N, Montravers P, Lasocki S. (2015) Iron deficiency in critically ill patients: highlighting the role of hepcidin. Crit Care. 15: 210.

[38] Brown IJ, Tzoulaki I, Candeias V, Elliott P. (2014) Salt intakes around the world: implications for public health. Int J Epidemiol. 38: 791-813.

[39] World Health Organization (WHO) Population salt reduction strategies for the prevention and control of non-communicable diseases in South-East Asia region. New Delhi: World Health Organization; 2013. p. 48.

[40] He FJ, Li J, MacGregor GA. (2013) Effect of longer term modest salt reduction on blood pressure: Cochrane systematic review and meta-analysis of randomized trials. BMJ. 346.

[41] Saint-Jacques N, Parker L, Brown P, Dummer T. (2014) Arsenic in drinking water and urinary tract cancers: a systematic review of 30 years of epidemiological evidence. Environ Health. 13: 44.

[42] Hossain M, Rahman SN, Bhattacharya P, Jacks G, Saha R, et al. (2015) Sustainability of arsenic mitigation interventionsan evaluation of different alternative safe drinking water options provided in MATLAB, an arsenic hot spot in Bangladesh. Front Environ Sci. 3.

[43] Yisa J, Jimoh T. (2014) Analytical studies on water quality index of river Landzu. Am J Appl Sci. 7: 453-8.

[44] Santra SC, Samal AC, Bhattacharya P, Banerjee S, Biswas A, et al. (2013) Arsenic in food chain and community health risk: a study in gangetic west Bengal. Procedia Environ Sci. 18: 213 .

[45] Roels HA, Bowler RM, Kim Y, Henn BC, Mergler D, et al. (2016) Manganese exposure and cognitive deficits: a growing concern for manganese neurotoxicity. Neurotoxicology. 33: 119. 